\title{
The Relationship between Stress and Job Satisfaction: An Evidence from Malaysian Peacekeeping Mission
}

\author{
Azman Ismail \\ Faculty of Economics \& Management, Universiti Kebangsaan Malaysia, 43600 Bangi, Selangor, Malaysia \\ Email: azisma08@gmail.com

\begin{abstract}
Ahmad Bashawir Abdul Ghani
International Affairs Management Department, School of International Studies,

Universiti Utara Malaysia, 06010. Sintok Kedah

Email: bashawir@uum.edu.my
\end{abstract} \\ Muhammad Subhan \\ International Business Management Department, School of International Studies, \\ Universiti Utara Malaysia, 06010. Sintok Kedah \\ Email:msubhan@uum.edu.my \\ Mohd Hasanur Raihan Joarder \\ School of Business Management, Universiti Utara Malaysia, 06010. Sintok Kedah. \\ Email: hasanur@uum.edu.my

\section{Ahmad Azan Ridzuan} \\ Faculty of Defence \& Management Studies, Universiti Pertahanan Nasional Malaysia \\ Sungai Besi Camp. 57000 Kuala Lumpur, Malaysia \\ Email: azan6142@yahoo.com
}

Doi:10.5901/mjss.2015.v6n4s3p647

\section{Abstract}

Recent studies on the relationship between job stress and job satisfaction have attracted significant attentions from researchers. The literatures on organizational stress, work related stress consists of two important dimensions: physiology and psychology. The ability of employees to appropriately handle stress in performing job may have a significant impact on individual outcomes, especially job satisfaction. Although the relationship is important, the role of work related stress as an important determinant has been given less attention in organizational stress research literature. Thus, this study was done to measure the association between work related stress and job satisfaction using self-report questionnaires collected from Malaysian peacekeeping personnel at a conflicting Middle Eastern country. The outcomes of testing hypothesis using SmartPLS path model analysis highlighted four important findings: first, physiological stress was significantly associated with job satisfaction. Second, psychological stress was significantly associated with job satisfaction. The finding confirms that work related stress does act as an important determinant of job satisfaction in the organizational sample. Further, discussion, implications and conclusion are elaborated.

Keywords: Human resource management, physiological stress, psychological stress, job satisfaction, peacekeeping mission; Malaysia, Middle East

\section{Introduction}

The International Labour Organisation (ILO) reported that almost 10 percent of workplace problems are stress-related, hence the organization's ability to effectively manage the stress of its emplyees can help the organisation sustains its performance (International Labour Organizsation-ILO, 2013). Such a situastion is common in military or security 
organizations. It is a well known fact that security personnel engaged in peacekeeping duties encounter numerous stressful situations that are often different to those encountered during combat operations (Greenberg et al., 2003). Working or operating under hard and restrictive rules of engagement and have to deliver humanitarian aid amidst politically chaotic environment that lead to the impacts upon the well-being, readiness and operational effectiveness are repeatedly assignments to peacekeeping personnels (Orsillo et al., 1998). Some peace-keeping operations are in highly volatile areas where the potential for exposure to traumatic incidents is very high. For example, a situation may involve the following scenarios: substantial possibilities of exposure to atrocities, horrible suffering and death; potentially and unpredictably dangerous and life-threatening situations; stress related to the use of weapons; immersion in a potentially hostile foreign culture; and strict rules of engagement (UNDPKO, 1995). According to yet another study, security personnels going on peacekeeping mission needed to be carefully screened to avoid taking those who could not cope with stress of the mission; that maintenance of cohesion and morale in theatre requires more attention (English, 2000).

Stress is often categorized as a form of uncountable and nonvisible pressure in nature. Stress is defined as the harmful physical and emotional responses that are evoked when the requirements of the job do not match the capabilities, resources, or needs of the worker. In general, stress is the non-specific negative response of the body in trying to meet the demands of the workplace (Yeboah et al., 2014). It manifests feeling of uneasiness due to pressure from internal and external sources that exerts someone for a result that is beyond an individual's ability to fulfill it by any mean (Saygin, Akdeniz, \& Deniz, 2015; Lazrus, 2013). Stress at organizational level is also called work related stress in reference to its relationship with individual (Low, Kok, \& Lee, 2014; Vijayalakshmi, Ramachandra, Reddemma, \& Math, 2014) as opposed to organizational (Saygin, Akdeniz, \& Deniz, 2015; Lazrus, 2013). Regardless, the matter of the fact is individuals (Low, Kok, \& Lee, 2014; Vijayalakshmi, Ramachandra, Reddemma, \& Math, 2014) work in industrial and organizational settings (Saygin, Akdeniz, \& Deniz, 2015; Lazrus, 2013) that require them to integrate at various degrees fully or partially, or even within the complete spectrum of integration, "tapered" integration included. Organizations tolerate stress, although they usually try to avoid it due to its objective driven focus (Ngo, Foley, Ji, \& Loi, 2014; Lazrus, 2013). Nevertheless, organizations adapt human resource process so that it can be addressed using the interpersonal and intrapersonal approaches. When organizations are concerned with issues of sustainability then any attempt to reduce human wellbeing and welfare will come under scrutiny (Ngo, Foley, Ji, \& Loi, 2014; Saygin, Akdeniz, \& Deniz, 2015; Lazrus, 2013). In achieving mutual benefit, organizations must adopt appropriate approaches to manage stress at all levels - organizational, occupational, local, transnational, and global, - in order to bring the workforce to a higher level of productivity, while operating in an uncertain environment. (Lazrus, 2013; Nielsen, Madsen, Bültmann, Aust, Burr \& Rugulies, 2013).

As a multidimensional construct, stress may be interpreted from two major perspectives: namely eustress and distress conditions (Selye, 1964, 1987; Ismail, Yao, Yeo, Lai-Kuan \& Soon-Yew, 2010). In an organizational context, eustress is often called positive stress where individuals have the adequate knowledge, skills, abilities and attitudes to cope with their work demands and pressures (Keshavarz \& Mohammadi, 2011; Yu-Fei, Ismail, Ahmad, \& Kuek, 2012; Code \& Langan-Fox, 2001; Gachter, Savage, \& Torgler, 2011). On the other hand, distress is also known as negative stress and this situation refers to individuals who do not have adequate knowledge, skills, abilities and attitudes to cope with external forces and challenges placed on their bodies (Ismail, Yao, Yeo, Lai-Kuan \& Soon-Yew, 2010; Keshavarz \& Mohammadi, 2011; Basowitz, Persky, Korchin, \& Grinker, 1995).

Work related stress refers to a state whereby individuals experience physiological stress (PHS) and/or psychological stresses (PSS) in carrying out duties and responsibilities to achieve their key performance indicators (Ismail, Yao, Yeo, Lai-Kuan \& Soon-Yew, 2010; Ismail, Suh-Suh, Ajis, \& Dollah, 2009; Santos, Barros, \& Carolino, 2010). PHS is more often than not, a physiological reaction of the body (e.g., abdominal pain, backache, chest pain, fatigue, headache, heart palpitation, lethargic, migraine, muscle ache and sleep disturbance) to various stimuli at the workplace that triggers stress and subsequently directly and negatively affects an individual's productivity, effectiveness, quality of work and personal health (Ismail, Suh-Suh, Ajis, \& Dollah, 2009; Santos, Barros, \& Carolino, 2010; World Health Organization, 2007).

Each country has its unique social factors and economic conditions that precipitate stress, both physiological and psychological, taking into account that the workforce of each country varies and all have their own distinct peculiarities (Yu-Fei, Ismail, Ahmad, \& Kuek, 2012; Ismail, Suh-Suh, Ajis, \& Dollah, 2009; Low, Kok, \& Lee, 2014; Vijayalakshmi, Ramachandra, Reddemma, \& Math, 2014). However in general, unemployment, life's pressures, cost of living and social economic status contribute significantly to stress, especially to those suffering from mental illness (Keshavarz \& Mohammadi, 2011; Yu-Fei, Ismail, Ahmad, \& Kuek, 2012; Low, Kok, \& Lee, 2014; Vijayalakshmi, Ramachandra, Reddemma, \& Math, 2014). Social situations, social interactions and social background greatly influence the level of motivation and satisfaction and this in turn can exert negative influence to the level of stress, both to the individual and to 
the organization (Ismail, Yao, Yeo, Lai-Kuan \& Soon-Yew, 2010; Yu-Fei, Ismail, Ahmad, \& Kuek, 2012; Ismail, Suh-Suh, Ajis, \& Dollah, 2009; Low, Kok, \& Lee, 2014; Saygin, Akdeniz, \& Deniz, 2015). Work related stress is primarily contributed by individual employees' social conditions (Ismail, Yao, Yeo, Lai-Kuan \& Soon-Yew, 2010; Yu-Fei, Ismail, Ahmad, \& Kuek, 2012; Low, Kok, \& Lee, 2014) and within the contexts (Saygin, Akdeniz, \& Deniz, 2015; Suh-Suh, Ajis, \& Dollah, 2009) lead to varying levels of influence (Ngo, Foley, Ji, \& Loi, 2014) on psychological stress (Low, Kok, \& Lee, 2014) and physiological stress (Vijayalakshmi, Ramachandra, Reddemma, \& Math, 2014).

Physiological stress usually manifests itself as bodily pain (Ismail, Yao, Yeo, Lai-Kuan \& Soon-Yew, 2010; Low, Kok, \& Lee, 2014) and sufferings (Yu-Fei, Ismail, Ahmad, \& Kuek, 2012; Ismail, Suh-Suh, Ajis, \& Dollah, 2009) as a result of contexts (Ismail, Suh-Suh, Ajis, \& Dollah, 2009; Vijayalakshmi, Ramachandra, Reddemma, \& Math, 2014) and social interactions (Keshavarz \& Mohammadi, 2011; Vijayalakshmi, Ramachandra, Reddemma, \& Math, 2014) that have potential to reduce the level of productivity (Ismail, Suh-Suh, Ajis, \& Dollah, 2009; Vijayalakshmi, Ramachandra, Reddemma, \& Math, 2014), efficiency, proficiency, and quality outcomes (Santos, Barros, \& Carolino, 2010; World Health Organization, 2007). In addition, loneliness and interpersonal problems reduce one's ability to rationalize and increase stress (Saygin, Akdeniz, \& Deniz, 2015). This situation therefore contributes to serious psychological stress in the workplace (Lazrus, 2013) and also long term physical sickness (Nielsen, Madsen, Bültmann, Aust, Burr \& Rugulies, 2013).

Psychological stress (PSS) refers to internal pressure (Low, Kok, \& Lee, 2014) due to substantial influence from internal and external (Vijayalakshmi, Ramachandra, Reddemma, \& Math, 2014; Ngo, Foley, Ji, \& Loi, 2014; Saygin, Akdeniz, \& Deniz, 2015) sources that result in an imbalance in one's feelings, senses, and sensors which in turn contributes to inability to cope with work and sustain pressure in the workplace (Vijayalakshmi, Ramachandra, Reddemma, \& Math, 2014; Ngo, Foley, Ji, \& Loi, 2014; Saygin, Akdeniz, \& Deniz, 2015; Lazrus, 2013). Sources of psychological stress include personal, intrapersonal, interpersonal, workplace, community, and the environmental contexts (Ngo, Foley, Ji, \& Loi, 2014; Saygin, Akdeniz, \& Deniz, 2015; Lazrus, 2013).

PSS is often seen as an emotional reaction experienced by an individual (such as anxiety and depression burnout, job alienation, hostility, depression, tension, anger, nervousness, irritability and frustration) as a result of stimulants from the workplace (Ismail, Suh-Suh, Ajis, \& Dollah, 2009; Santos, Barros, \& Carolino, 2010; Millward, 2005). It is observed that people with PSS tend to behave irrationally (Ngo, Foley, Ji, \& Loi, 2014); and this manifests as loneliness (Saygin, Akdeniz, \& Deniz, 2015) and they are usually emotionally deficient (Santos, Barros, \& Carolino, 2010; Millward, 2005; Saygin, Akdeniz, \& Deniz, 2015; Lazrus, 2013).

Extant studies in organizational stress reveal that the levels of PHS and PSS may have a significant impact on personal outcomes, especially job satisfaction (Antoniou et al., 2003; Stacciarini et al., 2004). According to many scholars, job satisfaction (JOS) refers to an individual's general feelings or preference of individual or ones attitudes towards his/her job and extent to which one is content with it (Archana, Seema, \& Sujatha, 2014). Job satisfaction may also be defined as the pleasurable emotional state resulting from the appraisal of one's job in achieving or facilitating the achievement of one's job values (Locke, 1969). In work related stress literature, several scholars broadly interpret that PHS, PSS and JOS are distinct, but strongly interrelated concepts. For example, the ability or inability of employees to appropriately manage their PHS and PSS when performing their job may either positively or negatively affect JOS in organizations (Antoniou et al., 2003; Stacciarini et al., 2004).

Even though the nature of this relationship is significant, the role of work related stress as an important determinant has been given little explanation in organizational stress research literature (Low, Kok, \& Lee, 2014; Vijayalakshmi, Ramachandra, Reddemma, \& Math, 2014; Ngo, Foley, Ji, \& Loi, 2014). Many scholars argue that this situation arises from previous studies that have emphasized much on describing work related stress concept. Employing a meta-analysis method to explain the characteristics of work related stress in particular organizational settings, implementing a simple survey method to assess respondent attitudes toward employee stress in executing job characteristics, and ignoring to quantify the effects of size and the nature of correlation between work related stress and job satisfaction. As a result, these studies provided insufficient findings to be used as useful recommendations to practitioners in understanding the difficulty of work related stress and formulating action plans for handling employee stress when executing job in high competitive organizations (Morrison, Farquharson, Bell, Johnston, Jones, Schofield, Allan, Ricketts, \& Johnston, 2013; Vijayalakshmi, Ramachandra, Reddemma, \& Math, 2014). Therefore, this scenario encourages the researchers to further discover the nature of this relationship.

The main objective of this study is to investigate the relationship between work related stress and the satisfaction with the job. It is expected that the findings of the study may provide useful recommendations to practitioners in understanding the difficulty of work related stress and formulating action plans for handling employee stress in high competitive organizations. Therefore, the study encourages researchers to further discover the nature of this relationship 
in the context of different samples other than the western world. The structure of discussion in this paper begins with providing theoretical and empirical evidences supporting the association between the variables. The SmartPLS version 2.0 was employed to measure the association between the variables. Finally, discussion, implications and conclusion were elaborated.

\section{Literature Review}

The concept of stress is a multidimensional, and it may be interpreted from two major perspectives i.e. eustress and distress conditions (Selye, 1987; Ismail, Yao, Lai-Kuan \& Soon-Yew, 2010). In an organizational context, eustress is often called positive stress which is beneficial for organizations where individuals have adequate knowledge, skills, abilities and attitudes to cope with their work demands and pressures (Keshavarz \& Mohammadi, 2011; Yu-Fei, Ismail, Ahmad, \& Kuek, 2012; Code \& Langan-Fox, 2001; Gachter, Savage, \& Torgler, 2011). On the other hand, distress is perceived as negative stress refering to individuals having no such positive attributes to cope with external forces and challenges placed on them (Ismail, et. al., 2010; Keshavarz \& Mohammadi, 2011). In the case of this study, work related stress has been conceptualised as physiological stress (PHS), and psychological stress (PSS) in carrying out duties and responsibilities to achieve key performance indicators (Ismail, et. al. 2010; Ismail, Suh-Suh, Ajis, \& Dollah, 2009; Santos, Barros, \& Carolino, 2010). The former is viewed as a physiological reaction of the body (e.g., abdominal pain, chest pain, fatigue, headache, lethargic, migraine, and sleep disturbance) to various stressful triggers at the workplace that directly and negatively affects an individual's productivity, effectiveness, quality of work and personal health (Ismail et al., 2009; Santos et al., 2010; World Health Organization, 2007). While, the later psychological stress (PSS) refers to internal pressure an employee feel (Low, Kok, \& Lee, 2014) due to substantial influence from internal and external environment (Vijayalakshmi, Ramachandra, Reddemma, \& Math, 2014; Ngo, Foley, Ji, \& Loi, 2014; Saygin et al., 2015) that result in imbalance in one's feelings and senses which in turn contributes to inability to cope with work and sustain pressure in the workplace.

As stated earlier, physiological stress can be defined as bodily pain and sufferings as a result of contexts (Ismail et al., 2009; Vijayalakshmi et al., 2014) and social interactions (Keshavarz \& Mohammadi, 2011) that has potential to reduce the level of individual productivity, efficiency, proficiency, and quality outcomes (Santos et al., 2010; World Health Organization, 2007). It is also important to pay our attention to the fact that the loneliness and interpersonal problems reduce one's ability to rationalize and increase stress, as argued by Saygin et al. (2015) which in turn creates a serious psychological stress in the workplace (Lazrus, 2013) and also long term sickness. It can be inferred that both types of stress are interlinked to each other, not isolated. PSS is often seen as an emotional reaction experienced by an individual (such as anxiety and depression burnout, job alienation, hostility, depression, tension, anger, nervousness, irritability and frustration) as a result of stimulants from the workplace (Ismail et al., 2009; Santos et al., 2010; Millward, 2005). People with PSS tend to behave irrationally (Ngo, Foley, Ji, \& Loi, 2014) and are emotionally deficient (Santos et al., 2010; Millward, 2005; Saygin et al., 2015; Lazrus, 2013) which ultimately affects their performance level. It is also documented in the previous literature that both PHS and PSS may have significant impact on individual outcomes especially on their job satisfaction (Antoniou et al., 2003; Stacciarini et al., 2004). Scholars broadly interpreted that PHS, PSS and Job satisfaction are distinct, but are strongly interrelated. For example, the ability or the inability of employees to properly manage their PHS and PSS while performing job may positively or negatively affect job satisfaction (Antoniou et al., 2003; Stacciarini et al., 2004). However, the role of work related stress as an important determinant of job satisfaction has been given little attention in organizational stress related research literature (Low, Kok, \& Lee, 2014; Vijayalakshmi et al., 2014; Ngo et al., 2014).

Stress has been conceptualised differently in the literature such as exhaustion, psychological strain, emotional distress, physical illness occur due to extreme level of stress in the workplace. Syele (1976) defines it a psychological reaction to certain threatening environmental events, while Riggio (2003) stated that it is physiological and/or psychological reactions to events that are perceived to be threatning or taxing. Similarly, Lazarus (1991) claimed that work related stress is the reaction resulting from employees' perception about a certain events in the workplace that is a threat or a challenge. Thus, it can be argued that work related stress is primarily focusing on both physiological and psychological state of an employee. The physical, mental, and psychological response of an individual to pressure from the work environment resulting behavioral patterns and attitudes that are deviance from usual expectations (Obiora, 2007; Lazarus \& Folkman, 1984).

Cohen (1980) believes that poor job performance is also one of the causes of stress. Perhaps, stress can have positive impacts on employee performance as some perform better under stress, though its negative impacts outweigh the positive impacts. However, extreme stress is so aversive to employees that they try to avoid it by withdrawing either 
psychologically, physically or by leaving the job entirely (Beehr \& Newman, 1978). It is commonly perceived that job stress and job satisfaction has been strognly related where the former one influencing the level of employees'satisfaction with the job in particular, and with the organization in general. In fact, job satisfaction has been the most frequent investigated topic of interest in the organizational research (Spector, 1997). According to Chandraiah et al., (2003), employee who experience high level of job stresses for a longer period of time, tend to have lower levels of job satisfaction and job performance, withdraw from work and experience greater sickness absence, and finally tend to have high levels of turnover intentions.

Peacekeeping operations involve military and often civilian personnel. The nature of peacekeeping operations has become increasingly complex and stressful (Dyk, 2009). Recently, it has become an interesting topic of interest for studying the relationship between stress and job satisfaction using the sample of members associated with peacekeeping mission (Anshel, 2000). There is an evidence that stress and job satisfaction are critically essential to the efficient and effective functioning of the organizations (Obiora \& Iwuoha, 2013). Along with other jobs such as police, doctors, and nurses, peacekeeping mission is also believed to be more stressful (Riggio, 2003). The common perception is that peacekeeping mission is, to some extant a volunteering job where members' satisfaction is quite important in order to carry out duties and responsibilities successfully in the mission. To be more specific, Malaysian law enforcement members are deployed in the peacekeeping mission in middle-eastern country Lebanon where it is assumed that high levels of violenece and social disorder within the nation are prevalent.

The most critical aspects of peacekeeping mission is to deal with unlawful, often dangerous, actions of citizens, there are factors such as abusive treatment in the workplace, organizational inefficiency, and general lack of social and managerial support (Koortzen, 1996). Even though there are plenty of supports on the relationship of work related stress and job satisfaction (e.g. Bemana, Moradi, Ghasemi, Taghavi, \& Ghayoor, 2013; Mansoor, Fida, Nasir, \& Ahmad, 2011). Thus, based on the previous literature review and the theoretical understanding on stress and job satisfaction, the researchers proposed the following hypotheses.

$\mathrm{H1}$ : The level of physiological stress is significant and negatively related to Malaysian peacekeeping mission members' job satisfaction.

$\mathrm{H} 2$ : The level of psychological stress is significant, and negatively related to Malaysian peacekeeping mission members' job satisfaction.

\section{Method}

A mixed method of survey and semi-structured interview was utilized in order to collect the data for achieving the proposed research objectives. This research design was appropriate in collecting correct, precise and quality data for statistical analysis (Cresswell, 1998; Sekaran \& Bougie, 2011). The study involved soldiers engaged under Malaysian Batallion (MALBATT) in the peacekeeping mission in middle-eastern country, Lebanon in particular. After a comprehensive and extensive literature review, a questionnaire was developed. Consequently, four experienced army officers includes the commander, a senior officer, an administrative officer and a logistic support staff with related work experience in peacekeeping mission were interviewed. The findings from the interview helped the researchers to comprehend the pattern of relationship and the characteristics of work related stress and job satisfaction in the context of the study. After that, a pilot study was conducted in order to confirm the content and format of the questionnaire for this study. Due to familiarity of the respondents with the national language i.e. Bahasa Malaysia, a back translation method was utilized from English to Bahasa Malaysia in order to enhance the validity of data from the survey, and thus, the research findings (Sekaran \& Bougie, 2011). The survey questionnaire has three major sections: 12 items of physiological stress and 3 items of psychological stress which were adapted from work related stress literature (Slaski \& Cartwright, 2003; Morrison et al., 2013; Beehr, Jex, \& Ghosh, 2001). Job satisfaction had 4 items that were adapted from Warr et al.'s (1979) job satisfacton scale. All items used in the questionnaires were measured using a 7-point Likert scale ranging from "strongly agree" representing 7 , and "strongly disagree" representing 1 . There are few demographic variables were also used as control variables because this study focused on employee attitudes. A convenient sampling technique was employed in order to distribute self-report questionnaires among the peacekeeping members. This technique was employed because of unavailability of the list of registered peacekeeping personnel for confidential reasons. Of the number, 142 useable questionnaires were returned to the researchers, yielding a 35.5 percent response rate which was acceptable as suggested by Krecjcie and Morgan (1970). Furthermore, the SmartPLS was used as recommended by scholars to analize data and to test the research hypotheses (Henseler et al., 2009; Riggle et al., 2009). 


\section{Results}

Majority of respondents in this study are male armed forces (96.5 percent), aged group from 21 to 40 years old, married army personnel comprises 59.2 percent, non-ranking staff, SPM/MCE/SPMV holders (66.2 percent), armed forces who served between 6 and 15 years (73.9 percent), and mostly first timers (95.1 percent) in peacekeeping mission. Table 1 shows the outcomes of confirmatory factor analysis. The values of average variance extracted (AVE) for each variable namely Physiological stress (PHS), psychological stress (PSS), and job satisfaction (JOS) were measured greater than 0.5 , to show that the variable has fulfilled the satisfactory standard of convergent validity (Henseler et al., 2009; Barclay et al., 1995; Fornell \& Larker, 1981). Besides, the table shows that all variables which have the diagonal values of the square root of AVE were greater than the squared correlation with other variables in off diagonal, showing that this condition has met the acceptable standard of discriminant validity (Henseler et al., 2009).

Table 1: The Outcomes of Confirmatory Factor Analysis

\begin{tabular}{|c|c|c|c|c|}
\hline Construct & AVE & PHS & PSS & JOS \\
\hline PHS & 0.8116 & $\mathbf{0 . 9 0 0 9}$ & & \\
\hline PSS & 0.7093 & 0.0105 & $\mathbf{0 . 8 4 2 2}$ & \\
\hline JOS & 0.6921 & -0.1136 & 0.4431 & $\mathbf{0 . 8 3 1 9}$ \\
\hline
\end{tabular}

Table 2 displays correlation between items and factors for the different variables, and the construct reliability analysis. In this study, the loading should exceed the specified minimum, 0.7 for every variable to be included for their own constructs in the model (Fornell \& Larker, 1981; Chin, 1998; Gefen \& Straub, 2005). Further, values larger than 0.8 were used to measure the composite reliability (CLR) and Cronbach's Alpha (CAP), demonstrating that the variables or instrument used for this study have maintained good internal consistency (Henseler, Ringle \& Sinkovics, 2009; Nunally \& Bernstein, 1994).

Table 2: The Results of Factor Loadings and Cross Loadings for Different Constructs and Construct Reliability Analysis

\begin{tabular}{|c|c|c|c|c|c|}
\hline Construct/ltem & PHS & PSS & JOP & CLR & CAP \\
\hline PHS: & & & & 0.981 & 0.980 \\
PHSa & 0.863 & & & & \\
PHSb & 0.947 & & & & \\
PHSC & 0.893 & & & & \\
PHSd & 0.933 & & & & \\
PHSe & 0.940 & & & & \\
PHSf & 0.927 & & & & \\
PHSg & 0.884 & & & & \\
PHSh & 0.901 & & & & \\
PHSi & 0.935 & & & & \\
PHSj & 0.859 & & & & \\
PHSk & 0.832 & & & \\
PHSI & 0.890 & & & 0.880 & 0.813 \\
PSS: & & 0.790 & & & \\
PSSa & & 0.850 & & & \\
PSSb & & 0.884 & & 0.919 & 0.889 \\
PSSc & & & 0.883 & & \\
JOS: & & & 0.921 & & \\
JOSa & & & 0.901 & & \\
JOSb & & & 0.910 & & \\
JOSc & & & & \\
JOSd & & & & \\
\hline
\end{tabular}

Table 3 expresses the descriptive statistics and result of Pearson correlation analysis. The constructs have the means vary from 4.0 to 5.7, representing that the PHS, PSS, JOP and JOS are stretching high to highest level respectively. To avoid the effect of serious collinearity problem (Hair, Anderson, Tatham, \& Black, 2006), the correlation coefficients for the relationship between the independent variables (i.e., PHS and PSS) and the dependent variable (i.e., JOS) have to 
be less than 0.90 . All results showed that the measurement scale used in this study has fulfilled the acceptable level in terms of validity and reliability of the measurement.

Table 3: Mean, Standard Deviation, and Pearson Correlation Analysis

\begin{tabular}{|c|c|c|c|c|c|}
\hline \multirow{2}{*}{ Variable } & \multirow{2}{*}{ Mean } & \multirow{2}{*}{ Standard Deviation } & \multicolumn{3}{|c|}{ Pearson Correlation Analysis } \\
\cline { 4 - 6 } & & & 1 & 2 & 3 \\
\hline 1. PHS & 4.0 & 1.64 & 1 & & \\
\hline 2. PSS & 5.3 & .92 & .08 & 1 & \\
\hline 4. JOS & 5.7 & .77 & $-.21^{*}$ & $.36^{*}$ & 1 \\
\hline
\end{tabular}

Note: Significant at ${ }^{* *} p<0.01$

The results of PLS path model are shown in Figure 1. The overall predictive strength of the model is indicated by the value of $R^{2}$ which is 0.43 meaning that the model might explain $43 \%$ of the variance about job satisfaction from these two constructs. According to Chin (1998) and Henseler et al. (2009), 43 percent is considered as quite substantial as the value of $R^{2}$ is interpreted as follows: 0.19 , weak, 0.33 , moderate and 0.67 , substantial. The model revealed two important findings: first, Physiological stress (PHS) significantly correlated with job satisfaction ( $\beta=-0.24 ; t=3.44)$, therefore $\mathrm{H} 1$ was supported. Second, Psychological stress (PSS) significantly correlated with job satisfaction ( $\beta=0.42 ; t=6.96)$, therefore $\mathrm{H} 2$ was supported. In short, this result proves that work related stress is an important determinant of job satisfaction in the organization.

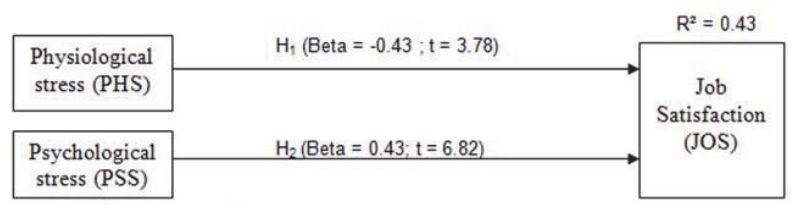

Note: Significant at ${ }^{*} t \geq 1.96$

\section{Figure 1: Outcomes of Testing PLS Path Model}

The global fit measure (GoF) was carried out based on Wetzel et al. (2009) guideline to determine whether the PLS path model has a global fit. The formula is as the following: GoF=SQRT\{MEAN (Communality of Endogenous) $x$ MEAN $\left.\left(R^{2}\right)\right\}=$ 0.43 , demonstrating that it exceeds the cut-off value of 0.36 for large effect sizes of $\mathrm{R}^{2}$. The result of the analysis confirms that the PLS path model has better explanatory power in comparison with the baseline values (GoF small $=0.1, \mathrm{GoF}$ medium $=0.25, \mathrm{GoF}$ large $=0.36$ ). It also provides adequate support to validate the PLS model globally (Wetzels, Odekerken-Schroder, \& van Oppen, 2009).

\section{Discussion}

This study has shown that work related stress in peacekeeping mission has an important contributing factor to armed forces' job satisfaction that influence their job performance. In the context of this study, Malaysia Batallion (MALBATT) has selected well trained soldiers to carry out peacekeeping mission in order to achieve the mission of the United Nations Interim Force in Lebanon. According to majority of the respondents, the levels of stresses (physiological and psychological stress) are high. The result of this study posits that majority of respondents feel that high levels of physiological and psychological stresses in executing challenging and unpredicted jobs in chaotic environments have reduced the ability of soldiers to improve job performance and job satisfaction in the peacekeeping mission.

This study has three important implications. First, with regard to theoretical contribution, the results of this study underscores that physiological and psychological stresses have been recognized as important determinants of job performance and job satisfaction. This result is consistent with as well as have broadened other studies such as by Antoniou et al. (2003), Stacciarini et al. (2004). Second,with regard to the robustness of research methodology, the measurement used in this study has satisfactorily met the acceptable standards of validity and reliability. This may lead to the production of accurate and reliable research findings. Third, with respect to practical contribution, the findings of this study may be used as guidelines by armed forces leadership to enhance the ability of soldiers in managing work related 
stress in challenging missions.

Due to distinctive nature of military job scope and orientation, human resource practices in private sector organizations may not be directly applicable. Despite this, there are a few suggestions that are appropriate for this study. First, ensuring that suitable administrative infrastructure be provided whenever feasible in order to facilitate the soldiers to accomplish their mission satisfactorily. In line with this, the senior officers should be provided with proper briefing on the specific components of the infrastructure and how to deploy them. Second, while maintaining the espirit de corps among the soldiers, the peace keepers need to enliven the spirit of peace keeping with forces from other countries as well. Third, the leadership of the army may want to assess its recruitment and selection policy for peace and similar missions so that it could deploy the same or adapted methodology to meet the needs of various volatile situations. The methodology should be able to match the right soldiers with the right jobs. Fourth, appropritate commendations in military environment for deserving soldiers play a powerful role in rewarding personnel selected to perform in special missions. Fifth, field stress training should be provided to all soldiers as part of their preparation to engage in special missions. If these suggestions are considered they may help the special forces to manage their stress at both individual and group levels.

\section{Conclusion}

This study has contributed to enrich the human resource management literature with a different working or research setting. The confirmatory factor analysis also has shown and acknowledged that the instrument used in this study fits with the acceptable standards of validity and reliability requirement. In addition, the model generated in this study revealed that physiological stress and psychological stress were significantly related to job satisfaction. The result also extended the work related stress studies to include a specifc case of peacekeeping mission. Therefore, organizations or employers are highly encouraged to consider employees' physiological and psychological stresses as one of the most important driving forces before embarking on any specific assignment especially international tasks. Moreover, this study recommends that the ability of employees to cope with physiological and psychological stresses in performing job will strongly enhance positive individual outcomes (e.g., performance, commitment and ethics). Therefore, these positive outcomes may lead to sustainable organizational strategy and goals.

\section{References}

AbuAlRub R.F. (2004). Job stress, job performance and social support among hospital nurses. Journal of Nursing Scholarship, 36(1), 73-78.

Anderson, R. (2003). Stress at work: the current perspective.The Journal of The Royal Society for the Promotion of Health, 123: 81

Anshel, M. H. (2000). A conceptual model and implications for coping with stressful events in police work. Criminal Justice and Behavior, 27(3), 375-400.

Antoniou, A.S.G., Davidson, M.J., \& Cooper, C.L. (2003). Occupational stress, job satisfaction and health state in male and female junior hospital doctors in Greece. Journal of Managerial Psychology, 8(6), 592-621.

Barclay, D. Higgins, C. and Thompson, R. (1995). The Partial Least Squares (PLS) approach to causal modeling: Personal computer adoption and use as an illustration. Technology Study, 2 (2), 285-309.

Basowitz, H. Persky, H. Korchin, S.J. and Grinker R.R. (1995). Anxiety and Stress. New York: McGraw-Hill Book Company, Inc.

Beehr T.A., Jex, S.M. and Ghosh, P. (2001).The management of work related stress. In Johnson, C.M., Redmon, W.K., \& Mahwhinney, T.C. (Eds.), Handbook of Organizational Performance: Behavior Analysis and Management. New York: The Haworth Press.

Beehr, T. A., \& Newman, J. E. (1978). Job stress, employee health and organizational effectiveness: A facet analysis, model and literature review. Personnel Psychology, 31.

Bemana, S., Moradi, H., Ghasemi, M., Taghavi, S. M., Ghayoor, A. H. (2013). The relationship among job stress and job satisfaction in Municipality personnel in Iran. World Applied Sciences Journal, 22(2), 233-238.

Bohlander, G. Snell, S. and Sherman, A. (2001).Managing human resources, South-Western College Publishing, Australia.

Chandraiah, K., Agrawal, S., Marimuthu, P., \& Manoharan, N. (2003). Job satisfaction among managers. Indian Journal of occupational and Environmental Medicine, 7(2).

Cresswell, J.W. (1998).Qualitative inquiry and research design: Choosing among five traditions. London: SAGE Publications,

Code, S and Langan-Fox, J.( 2001).Motivation, cognitions and traits: Predicting occupational health, well-being and performance. Stress and Health, 17, 159-74.

Dyk, G. A. J. (2009). The role of military psychology in peacekeeping operations: The South African National Defence force as an example. South African Journal of Military Studies, 37(1), 113-135.

Gachter, M Savage, D.A. and Torgler B. (2011).The relationship between stress, strain and social capital. Policing: An International Journal of Police Strategies \& Management, 515-540.

Gefen, D. and Straub, D. (2005).A practical guide to factorial validity using PLS-Graph: Tutorial and annotated example. Communication of the Association for Information Systems, 16, 91 - 109. 
Hair, J.F. Anderson, R.E. Tatham, R.L. and Black, W.C. (2006). Multivariate data analysis. New Jersey: Prentice Hall International, Inc. Health and Safety Executive. (2001). Help on Work related Stress: A Short Guide. INDG281 Rev1 2001.Sudbury: HSE Books.

Henseler, J. Ringle C.H., and Sinkovics R.R. (2009) .The use of partial least squares path modeling in international marketing. New Challenges to International Marketing. Advances in International Marketing, 20, 277-319.

Hsieh, Huang, and Su, K-J. (2004). Work stress and job performance in the hi-tech industry: A closer view for vocational education. World Transactions on Engineering and Technology Education, 3(1), 147-150.

Ismail, A. Suh-Suh Y., Ajis, M.N. and Dollah, N.F. (2009). Relationship between Work related stress, Emotional Intelligence and Job Performance: An Empirical Study in Malaysia. Theoretical and Applied Economics, 10 (539), 3-16.

Ismail, A. Yao, Yeo, E, Lai-Kuan, K., \& Soon-Yew, J. (2010). Work related stress Features, Emotional Intelligence and Job Satisfaction: An Empirical Study in Private Institutions of Higher learning. Revista Negotium,16 (5) 5-33.

Johnston, D. Jones M., Charles, K. McCann, S. and McKee, L. (2013).Stress in nurses: Stress-Related Affect and Its Determinants Examined Over the Nursing Day. Annals of Behavioral Medicine, 45(3), 348-356.

Ismail, A., Yao, A. and Yeop Yunus, N.K. Relationship Between Occupational Stress and Job Satisfaction: An Empirical Study in Malaysia. Romanian Economic Journal, 2009, 12 (34), 3-30

Karasek, R., \& Theorell, T. (1990). Healthy work: Stress, productivity, and the reconstruction of working life. New York: Basic Books.

Keshavarz, M., \& Mohammadi, R. (2011). Work related stress and Organizational performance, Case study: Iran. Procedia - Social and Behavioral Sciences, 30, $390-394$.

Koortzen, P. (1996). The dimensionality of police stressors. Acta Criminologica, 9(2), 55-63.

Krecjcie, R.V. and Morgan, D.W. (1970). Determining sample Size for Research Activities. Journal of Education and Psychological Measurement, 30, 607-610.

Lazrus R.S. (2013). Psychological stress in the workplace. Fifty Years of the Research and Theory of Rs Lazarus: An Analysis of Historical and Perennial Issues, 312.

Low, S.K. Kok, J.K. and Lee W.Y. (2011). Perceived Discrimination and psychological distress of Myanmar refugees in Malaysia. International Journal of Social Science and Humanity, 4 (3), 201-211.

Mansoor, M., Fida, S., Nasir, S., Ahmad, Z. (2011). The impact of job stress on employee job satisfaction: a study on telecommunication sector of Pakistan. Journal of Business Studies Quarterly, 2(3), 50-56.

Millward, L. (2005).Understanding Occupational and Organizational Psychology. Thousand Oaks, California: Sage Publications.

Morrison, K. Farquharson, B. Bell, C. Johnston, D. Jones, M. Schofield, P. Allan, J. Ricketts, I., \& Johnston, M. (2013). Nursing stress and patient care: real-time investigation of the effect of nursing tasks and demands on psychological stress, physiological stress, and job performance: study protocol. Journal of Advanced Nursing, 69 (10), 2327-2335.

Ngo H.Y., Foley S., Ji, M.S. and Loi R. (2014). Work satisfaction of Chinese employees: A social exchange and gender-Based view. Social Indicators Research, 116 (2), 457-473.

Nunally, J.C. and Bernstein, I.H. (1994). Psychometric Theory. New York: McGraw-Hill.

Obiora, C. A., \& Iwuoha, V. C. (2013). Work related stress, job satisfaction and due process in Nigerian public service. European Scientific Journal, 9(20), 214-232.

Riggio, R. E. (2003). Introduction to Industrial/Organizational Psychology, 4th edition, UpperSaddle, N. J: Prentice-Hall.

Santos, M. C., Barros, L., \& Carolino, E. (2010).Work related stress and coping resources in physiotherapists: a survey of physiotherapists in three general hospitals. Physiotherapy, 96, 303-310.

Saygin, Y., Akdeniz, S., \& Deniz, M. E. (2015). Loneliness and interpersonal problem solving as predictors of subjective well-being. International Journal of Information and Education Technology, 5 (1), 32-35.

Sekaran, U., \& Bougie, R. (2011). Research methods for business: A skill building approach. United Kingdom: John Wiley \& Sons, Ltd.

Selye, (1987). Stress without distress, London: Transworld.

Slaski, M., \& Cartwright, S. (2002). Health, Performance and El: An exploratory study of retail managers. Stress and Health, 18(2), 6368.

Stacciarini, J.M.R. (2004). Occupational stress and constructive thinking: Health and job satisfaction. Journal of Advanced Nursing, 46(5), 480-487.

Warr, P. B., Cook, J., \& Wall, T. D. (1979). Scales for the measurement of some work attitudes and aspects of psychological well-being. Journal of Occupational Psychology, 52, 129-148.

Wetzels, M., Odekerken-Schroder, G., \& Van Oppen, C. (2009). Using PLS path modeling for assessing hierarchical construct models: Guidelines and empirical illustration. MIS Quarterly, 33 (1), 177-195.

Yu-Fei, C., Ismail, A., Ahmad, R., \& Kuek, T.Y. (2012). Impacts of job stress characteristics on the workforce - organizational social support as the moderator. South-Asia Journal of Marketing and Management Research, 2(3), 1-20. 